\title{
Factors affecting the software developer's performance
}

\author{
Bibhushan Raj Joshi * \\ School of Business and Management, Bandung Institute of Technology, Bandung, Indonesia
}

\author{
Keywords \\ Competitive advantage \\ IT industry \\ Strategic management \\ Employee behavior
}

Received: 5 October 2018

Accepted: 12 November 2018

Published: 11 December 2018

\begin{abstract}
To understand the demand of the constantly changing software market environment, the known attributes and factors of employee behavior such as team size, requirements, innovation, culture, experience, and software development frameworks should be considered to make decisions. The interrelation between these available resources helps to understand the developmental process better and attain the better result. This paper examines and compares the sustainable key factors in the IT companies of Nepal to get a better understanding of the factors which can help the companies grow and maintain their position in the market. For this study, the factors defined by Clarke and O'Connor (2012) were carefully looked at and closely compared with the reviews from the software developers. This research was done based on questionnaires asked between software developers and a group of freelancers and a semi-structured interview conducted with the CEO of two software companies. The result suggests that the employee attitudes were highly dependent on some factors defined by Clarke and O'Connor (2012) which was later compared with Sobhani, Wahab, and Neumann (2017) employee performance factors to provide a perspective of employee behavior and decision making. Finally, the study sorts the result based on the priority and provides a new perspective gained during the research, which could aid in strategic decision-making for sustainable growth in the software industry. The software industry of Nepal is still in the growing phase, and many changes are going on within a short time frame. Close monitoring of the factors affecting the software developer's behavior and satisfaction level will help managers comprehend their employees' needs better and take a proper coordinated decision.
\end{abstract}

(C) 2018 The Author(s). Published by TAF Publishing.

\section{INTRODUCTION}

Employees are vital part of a company. They are the one which defines the performance of an organization and directs the organization towards it vision. By motivating the employees and providing them with their needs helps in the performance and company's growth (Kurniawati \& MeilianaIntani, 2016; Sirota \& Klein, 2013; Vosloban, 2012). The competitive environment (Zahra \& Bogner, 2000) which exists within the software industry makes it more important for the organization to motivates its software developers through different medium such as incentives, rewards, and others.

Nowadays, the interaction and performance of the team plays a vital role for getting the things done in a project (Asproni, 2004; Mahdieh, 2015). Like an individual, team have different personality and ability to get the task done. According to Katzenbach and Smith (2005), a team is de- fined as a leadership roles, collective work results, motivation for open minded discussion, collective work and problem solving. This applies for the software development team as well where all the developers are working for a common goal to create an application, provide a service or other list of tasks defined in their work schedule.

Software industry has been growing rapidly in these past decades. The low investment required in the development of software has given rise to number of companies and challenges. The highly competitive environment where innovation driven by novel, complex, performance driven, cost effective and profit driven multi-layer product is to be created (Muenthaisong \& Leemanonwarachai, 2016; Porter \& Heppelmann, 2014). So unlike any other organization, software industry's working environment and the result are totally based on the involvement and initiation that an employee can put forward in their project. Due to the changing envi-

\footnotetext{
*corresponding author: Bibhushan Raj Joshi

†email: bibhushan_raj@sbm.itb.ac.id
} 
ronment and growing competition, the organization need a maximum effort from the employees to grow and sustain in the business. The rise of digital age has given new opportunities to the people and has given rise to new jobs and industries. In Nepal, major software companies are growing in an exponential rate (The Himalayan, 2018). The software companies are providing services and creating application for both local and foreign parties. Basically the off-sourced software are usually from countries like US, India and European countries (Xtend, 2017). For which, the companies are even following the international standards and developmental processes such as Software Development Life Cycle (SDLC), Agile principles and Scrum methodologies. Accordingly, some initiation has been taken to develop their employee standards and growth. This paper further looks and evaluates the factors affecting the performance of the employee to provide new insights and aid in the decision making of the managers.

The future of software industry is filled with more challenges and unprecedented growth (David, 2000; Dingsøyr, Dybå, \& Moe, 2010; Northrop et al., 2006; Rahman \& Qi, 2016). This requires company to be prepared for future needs to promote employee development. The critical analysis of software developer performance will help us better learn about their behavior and needs. To help in this understating complexity of different factors such as environment, salary, team work, recreation, culture and others a can be evaluated. This paper looks in the aspects of employee development and factors encouraging those behaviors. The recognition and tackle of the performance problem and useful decision-making helps both employee and manager, which in long term allows to gain sustainable and effective management.

\section{LITERATURE REVIEW}

The growth and success of the company is highly dependent on the performance of an organization. The effectiveness of an organization to achieve a reliable performance helps in its path towards sustainable growth. The evaluation of performance has been a complicated topic for which financial measures has been used as a factor to evaluate performance. But a conceptual research and findings has found different factors related to performance measurement. Many researchers have found performance measurement tends to update and continuously change (Bourne, Mills, Wilcox, Neely, \& Platts, 2000; Dixon, 1990; Ghalayini \& Noble, 1996; Hang, 2015; Meyer \& Gupta, 1994). Waggoner, Neely, and Kennerley (1999) found that the key forces driving the change are information technology, cus- tomers, market, public policy and laws, new industries, nature of work and uncertain future. Later on, Greiner (1996) categorized inhibiting factors as institutional, pragmatic, technical and financial.

In the paper Islami, Mulolli, and Mustafa (2018), the author describes about the importance of the Management by Objectives. The employee satisfaction is based on clear definition and objectives of work and proper standards for motivating employee within a given time and budget. Besides that, the continuous horizontal, vertical, formal, non-formal, oral or written means of communication, evaluation of individual performance and employee's behavior are predictive based on reward and incentivebased system. The implementation of MBO based system helps to create opportunities and helps the company to increase and survive by improving their employee's performance. The growth and improvement of the employee results in the overall growth of the organization as a whole (Antonacopoulou, 2000; Tsai \& C, 2017). According to Hameed and Waheed (2011), employee development is based on skill growth, employee learning curve, self-direction, employee's attitude and behaviors. The improvement of the values of employee development results in employee performance and ultimately allows an organization to gain an effective growth.

Alefari, Fernández Barahona, and Salonitis (2018) mentioned the main factors affecting employee performance are Employee well-being, Motivation and Attention to details. Employee well-being defines the physical and mental health of an employee which helps in knowing the economic aspects as well (Sobhani et al., 2017). Motivation depends on the various factors of work environment, team, rewards and other attributes which encourages the employees. Attention to detail constitutes of periodical correction and review of work. Besides that, there are different secondary factors such as adaptability, learning, job satisfaction, organizational commitment, competition, flexible working hours, external environment and absenteeism. By considering all these factors Alefari et al. (2018) has defined a model to improve the initiatives on the employee performance and gain a sustainably of high performance from the employees.

\section{Motivation and Encouragement}

The importance of motivation to gain a better return has been understood by researchers (Asproni, 2004; Noe, Hollenbeck, Gerhart, \& Wright, 2006). Several methods such as training and development, reward system, HR planning, recruitment, promotion and others can be used to build up 
the employees' performance. But for that, regular track and understanding of employee behavior plays a vital role.

The performance of an employee highly depends on the satisfaction between the individuals undertaking the task within a project. Employee Trust plays a vital role in gaining a feedback and maintaining a proper relationship with a manager (Sharkie, 2009). According to Fuss (1983), the job satisfaction of software developers is based on clear communication of advancement opportunities, frequent praise for good job, allowing the developers to share their learned lesson throughout the organization, ensuring the developers work in impactful activity, facilitate individualistic reward and recognition, and ensuring compensation does not become the source of dissatisfaction. Managers need to keep in to account of all these factors to ensure a satisfying and a productive employee.

\section{Factors Affecting Performance}

Sawyer and Guinan (1998) studied 40 software teams to know the effects of social aspect and production method on a team performance and software quality. From the study, it was known that the use of automated development tools and software methodologies had no explanation for changes in software development team performance. While according to Curral, Forrester, Dawson, and West (2001), team objectives performance, strategies and processes are outcome of the quality. Besides that, poor project management impacts the team performance, and the improvement of performance of software team is based on team size and extent of software reuse (Ramasubbu \& Balan, 2007). The technical factors like knowledge of source code, source code reuse and source code complexity also affect the productivity of a developer (Haefliger, Von Krogh, \& Spaeth, 2008; Hassan, 2009). Apart from that team member's skills, experience, knowledge and abilities have an impact on team performance (Blasi, Fiore, Hedberg, Schmid, et al., 2008). In case of software developers instances has shown that, a properly maintained environment can result in better satisfaction and performance (Baddoo, Hall, \& Jagielska, 2006). The IT field has been growing in an exponential rate throughout the recent decade, but there has been few framework or study of software developers and individuals to analyze their factors affecting their satisfaction and performance level. Recently Clarke and O'Connor (2012) provided a framework by including rage of domains and situational factors. It included a ten-step process to identify the factors affecting the software processes. The method provides a reasonable base for the numerous factors affecting the software development process. The actual implemen- tation and evaluation of this framework in the real working environment provided a better understanding of its usefulness and the practicality of the processes. A valid information is extracted using the different available domain associated with the software development situational factors such as risk factors, cost estimation, environmental factor, process tailoring, degree of process agility and body of knowledge. The data sources were compared and analyzed to find 44 unique factors and its 170 sub-factors. These factors give a comprehensive reference framework to understand the processes within the software development team and undertake a strategic decision.

\section{Nepal Software Industry}

Software industry in Nepal is in its beginning stage and most of work are usually from India, US and European software companies (Xtend, 2017). Cheap labor and high-quality application have attracted lot of foreign and local investor. But to satisfy the increasing demand and the quality of the product, proper monitoring of the developers is crucial. By knowing the factors affecting the employee's motivation and by executing effective management, strategic and impactful decision should be undertaken to gain long-term advantage. So, the growing state of Nepalese software industry can benefit a lot by analyzing the need and behavior of their employees, which in terms will help to gain sustainable advantages and international recognition.

\section{RESEARCH METHODS AND DESIGN}

This research was done based on questionnaires asked between software developers and group of freelancers and a semi-structured interview conducted with CEO of two software company. A qualitative method was compared with Clarke and O'Connor (2012) factors to apply the factors and capabilities affecting the behavior of the software developers. Previous theory mentioned in the literature review is used as base to find it usefulness in Nepal. The research data was based on two software company and freelancers based in Nepal. From the total of 52 employees in one company 33 individuals participated in the research, while only 18 individuals from another company participated in the event. The rest of 45 individuals were freelancers. The questionnaires for the participants was multiple choice with a feedback box in each question for detail explanation. The question based on participants questionnaires was used to interview two CEO with their views regarding the motivation, well-being and attention to details regarding employee performance.

For this study, the factors defined by Clarke and O'Connor 
(2012) is used as a base to identification and verification. There are 44 factors and 170 sub factors affecting the judgement of a software developer which has been divided in 8 classification. But since we were taking software developers point of view and our questionnaires result were based on their answer. The average of the total sum of response from the software developers for each situation factor was used to know the priority of the software developers. From the list of answer, the value matching the particular situational factors was later sorted according to the average value obtained from the research.

The statistical analysis was done to know the factors affecting the software developer's decision making. The individual data from each participant was gathered and the calculated total value for each situational factor was done to measure their behaviors. The average calculated from the collected data for each situation factors in the Figure 1 and Figure 2 was generated at the end to show the correlations between the different factors and its significance to the software developers' performance. The business factor was eliminated, as the software developers usually had less knowledge and experience with elements included in this factor. So, the major factors evaluated are organization, operation, personnel, technology, requirement, management and application. The positive factors for disharmony and changeability are used as harmony and less changeability respectively, to summarize the positive sub-factors affecting the major factors.

The situational factors have been classified into 7 groups 1. Personal: characteristic of non-managerial individual involved in software development process.

2. Requirements: characteristics of requirements.

3. Application: characteristics of applications under development.

4. Technology: provides a characteristic of technology being used for the software development.

5. Organization: provides characteristics of an organization.

6. Operation: provides operational considerations.

7. Management: provides characteristics of the software team.

TABLE 1. Definition of Clarke and O'Connor (2012) sub-factors

\begin{tabular}{|c|c|c|}
\hline Major Factor & Sub Factor & Definition \\
\hline \multirow[t]{6}{*}{ Organization } & Maturity & Maturity of programming practices, technology and organization \\
\hline & Management Commitment & Commitment from senior management \\
\hline & Stability & Stability of resources \\
\hline & Structure & Organizational structure \\
\hline & Facilities & Working arrangement \\
\hline & Organization Size & Size of an organization \\
\hline \multirow[t]{2}{*}{ Operation } & End-Users & Users engagement and changeability which affects the systems capability and requirements \\
\hline & Prerequisites & Applicable standards, laws, policies, practices, operation and ease of use \\
\hline \multirow[t]{9}{*}{ Personnel } & Turnover & Personal return \\
\hline & Team Size & Size of a team \\
\hline & Culture & Team culture \\
\hline & Experience & $\begin{array}{l}\text { Experience of team, individual, managers, analyst, programmer or tester with software development } \\
\text { or platform }\end{array}$ \\
\hline & Cohesion & Cohesion among team member to do defined projects or task \\
\hline & Skill & Ability such as operation, analysis, programming, team expertise etc. \\
\hline & Productivity & Teams ability to carry task effectively and efficiently \\
\hline & Harmony & No conflicts \\
\hline & Commitment & Commitment among team-members \\
\hline \multirow[t]{2}{*}{ Technology } & Knowledge & Knowledge/Experience regarding tools, language, technology, projects, hardware software in need \\
\hline & Emergent & Latest technology \\
\hline \multirow[t]{4}{*}{ Requirements } & Less changeability & Less changing requirement, clearly defined projects \\
\hline & Standard & Quality of output, system requirements, user engagement and understanding \\
\hline & Rigidity & Rigidity of compliance requirements \\
\hline & Feasibility & Feasibility of programming and technical capability \\
\hline \multirow[t]{3}{*}{ Management } & Continuity & Managerial changes in organization \\
\hline & Expertise & Expert in project management, planning, governance, estimation and other aspect of management \\
\hline & Accomplishment & Experience of project management or operational leader \\
\hline \multirow[t]{2}{*}{ Application } & Quality & Product quality or maintainability \\
\hline & Deployment Profile & Number of deployed versions of application \\
\hline
\end{tabular}




\begin{tabular}{lll} 
Table 1. Continue.. & \\
\hline \hline Major Factor & Sub Factor & Definition \\
\hline Development Phase & Developmental phase \\
Component Reuse & Reuse of component \\
Connectivity & Link to existing or future system \\
Complexity & Software, hardware or task complexity \\
Type & Application type, domain, architecture, configuration or recovery \\
Application Size & Application size or required storage \\
Predictability & Platform volatility or changes \\
Performance & Performance of hardware, requirements, reliability and capability of software \\
Degree of Risk & Number of department or individual the project affects \\
\hline \hline
\end{tabular}

To understand the step taken by the management, a semistructured interview was done with the CEO of two software companies. The question made for the CEO was based on the factors defined by Clarke and O'Connor (2012) and the major factors defined by Alefari et al. (2018). The current steps taken by the software company was identified and well recorded.

The determined factors by the above method was then further categorized based on the different performance factors (Sobhani et al., 2017). This helps to understand the exact factors affecting the employee's behavior and decision making. Though each performance factors are equally impor- tant, according to these result the manager can set his priorities.

\section{FINDINGS AND DISCUSSIONS}

The objective of this study is to find the of employee behavioral factors affecting the performance of software company in Nepal. The data collection for seven major factors and 37 sub-factors defined by Clarke and O'Connor (2012). The answers from the questionnaires was used to gather the information regarding the topic. The closely dependent relation with these factors within software industry of Nepal definitely can be seen from Figure 1 .

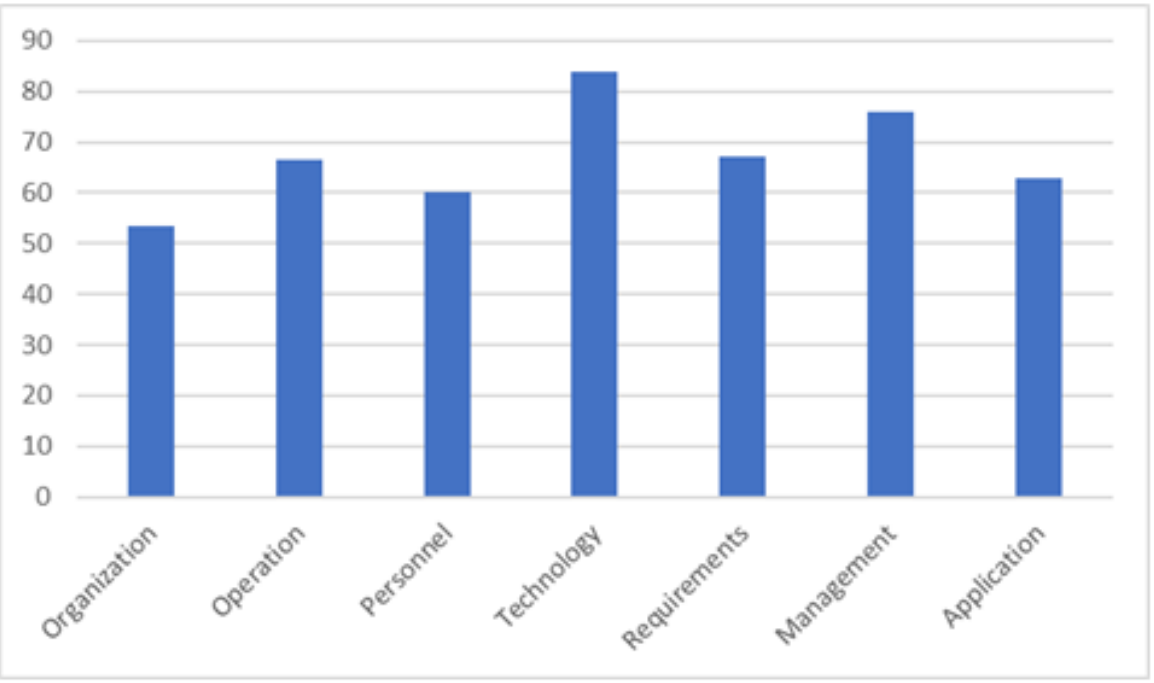

FIGURE 1. Average of 7 major factors collected from the survey

From the answers collected from the group of 96 individuals, the majority of developers agreed in being technology as a major factor as the research was done in a software industry. So, the understanding and regular updates about the technology plays a vital role in the software development process. Management is the second factor that plays an important role as it plays a major role in maintaining the team member coordination and their organization. Afterwards
Operation and Requirements plays almost an equal contribution in smooth flow of software development processes. In the notes many of the software developers has mentioned that a clear and properly maintained requirements saves times and motivates them to approach a project with enthusiasm. The other factors are personnel needs and application and organizational structure. The detailed sub-factors affecting these values is shown in the Figure 2. 




FIGURE 2. Regional geology of Bojan coal deposit at Vientiane province, Lao PDR (Data source from Lao Stage Enterprise Company)

The emergent of latest technology is regarded as a most important factor by the software developers for getting the software projects done. The other factors such as type, connectivity, component reuse, commitment, knowledge, fea- sibility accomplishment, team size, prerequisites and stability are also considered as a success factor within a software project and a software industry. The factors defined by Sobhani et al. (2017) were also directly related with the 
sub-factors and feedbacks received from the respondents and CEO of the company. The Employee well-being, Motiva- tion and Attention to details were basically affected by subfactors as mentioned below.

TABLE 2. Sobhani et al. (2017) Employee performance factors based on Questioners and Interview

\begin{tabular}{lll}
\hline \hline Motivation & Well Being & Attention to Details \\
\hline Stability & Stability & Management Commitment \\
Facilities & Maturity & Prerequisites \\
Harmony & Facilities & End Users \\
Feasibility & Productivity & Commitment \\
Accomplishment & Experience & Quality \\
Expertise & Turnover & Expertise \\
Turnover & Accomplishment & Cohesion \\
Continuity & Experience & Standards \\
Technology & Cohesion & Deployment Profile \\
Less Changeability & Feasibility & \\
\hline \hline
\end{tabular}

The factors are categorized according to the feedbacks and answers from the questionnaires and interview. These data give us a better understanding of the software developers behavior. Also provides details look into different factors affecting the performance of an individual in different ways. Other factors such as team size, developmental phase, deployment profile, connectivity, component reuse is regarded as factors which aids in the performance by the means of easiness and helpfulness, rather than directly affecting the motivation or well-being of a software developer. The CEOs of the companies mentioned that, they are following the same rules set by the startup in US and are using the methodologies of Scrum and Agile principles to deliver quality product to their clients and for better employee management. They agreed that the software industry is highly demanding and competitive business, and developer plays a vital role to tackle those challenges. Currently, the developers are being provided with proper facilities such as appropriate salary, technological needs, online learning facilities, capable team members. But they accepted that since they were mostly following steps taken by other companies, it would be better if specific or important demands of employee could be strategically fulfilled to encourage better performance and decrease turnover rates.

\section{CONCLUSION \& IMPLICATIONS}

For every organization, employee is a valuable means of their growth and development. The understating of the employee's behavior and maintaining a proper environment and interaction within the organization is crucial. In a software industry, same goes for the software developers. The understanding of the needs and requirements of the software developer plays an important role to get a maximum performance from them to ultimately gain a profit. The study on this paper was done based on the major factors defined by Clarke and O'Connor (2012). In terms of software developer based on Nepal, the major factors needed for their satisfaction are latest technology, connectivity, less changeability, component reuse, commitment, knowledge, feasibility, accomplishment, team size, prerequisites and stability. The sorting was done by weighing the response to each situational factor, highest being the one which was agreed by most of the software developers in the questionnaires for being the root cause of their performance. While the factors like rigidity, organization size and application size are disregarded by the developers. The priority for the factors is given in the order: Technology, Management, Operation, Application, Personnel, and Organization. Based on this, the company could provide training and manage their faculty by targeting specific factors and understanding employee's needs perspectives (Wrzesniewski \& Dutton, 2001). The organization has been the least favorable because most of the individuals are working as a independent programmer without being bounded by the organizational rules.

The software industry of Nepal is still in the growing phase and lot of changes are going within a short time frame. A close monitoring of the factors affecting the software developer behavior and their satisfaction level, will help the managers to better comprehend their employees needs and take a proper coordinated decision. Thus, in the competitive world of software development, long-term successful growth of an organization can be attained based on the employee performance and satisfaction.

The employee performance is a constantly changing pro- 
cess which depends on time, place, industry and many more (Bourne et al., 2000; Dixon, 1990; Ghalayini \& Noble, 1996; Meyer \& Gupta, 1994). Employee performance could be further explored by addition of new factors and monitoring the factor's deviance from the original value with regar- dance to passage of time or change in location. All the additional factors, improvements and correction should help adapt with the changing requirement of employee management and understand their needs, which will ultimately aid Industrial leaders to better managerial decision.

\section{REFERENCES}

Alefari, M., Fernández Barahona, A. M., \& Salonitis, K. (2018). Modelling manufacturing employees' performance based on a system dynamics approach. Procedia CIRP, 72(5), 438-443. doi:https://doi.org/10.1016/j.procir.2018.03.161

Antonacopoulou, E. P. (2000). Employee development through self-development in three retail banks. Personnel Review, 29(4), 491-508. doi:https://doi.org/10.1108/00483480010296294

Asproni, G. (2004). Motivation, teamwork, and agile development. Agile Times, 4(1), 8-15.

Baddoo, N., Hall, T., \& Jagielska, D. (2006). Software developer motivation in a high maturity company: A case study. Software Process: Improvement and Practice, 11(3), 219--228. doi:https://doi.org/10.1002/spip.265

Blasi, L., Fiore, S. M., Hedberg, J., Schmid, R. F., et al. (2008). Research on educational communications and technology. Mahwah, NJ: Lawrence Erlbaum Associations.

Bourne, M., Mills, J., Wilcox, M., Neely, A., \& Platts, K. (2000). Designing, implementing and updating performance measurement systems. International Journal of Operations \& Production Management, 20(7), 754-771. doi:https://doi.org/ 10.1108/01443570010330739

Clarke, P., \& O'Connor, R. V. (2012). The situational factors that affect the software development process: Towards a comprehensive reference framework. Information and Software Technology, 54(5), 433-447. doi:https://doi.org/10.1016/ j.infsof.2011.12.003

Curral, L. A., Forrester, R. H., Dawson, J. F., \& West, M. A. (2001). It's what you do and the way that you do it: Team task, team size, and innovation-related group processes. European Journal of Work and Organizational Psychology, 10(2), 187-204. doi:https://doi.org/10.1080/13594320143000627

David, P. A. (2000). Understanding digital technology's evolution and the path of measured productivity growth: present and future in the mirror of the past. Cambridge, MA: Massachusetts Institute of Technology.

Dingsøyr, T., Dybå, T., \& Moe, N. B. (2010). Agile software development: Current research and future directions. New York, NY: Springer Science \& Business Media.

Dixon, J. R. (1990). The new performance challenge: Measuring operations for world-class competition. Huntersville, NC: Irwin Professional Pub.

Fuss, J. A. (1983). A systems design to measure productivity of software developers for production systems (Unpublished doctoral dissertation). Northwestern University, Illinois, IL.

Ghalayini, A. M., \& Noble, J. S. (1996). The changing basis of performance measurement. International Journal of Operations \& Production Management, 16(8), 63-80. doi:https://doi.org/10.1108/01443579610125787

Greiner, J. M. (1996). Positioning performance measurement for the twenty-first century. Organizational Performance and Measurement in the Public Sector, 4(6), 11-50.

Haefliger, S., Von Krogh, G., \& Spaeth, S. (2008). Code reuse in open source software. Management Science, 54(1), 180-193. doi:https://doi.org/10.1287/mnsc.1070.0748

Hameed, A., \& Waheed, A. (2011). Employee development and its affect on employee performance a conceptual framework. International Journal of Business and Social Science, 2(13), 34-50.

Hang, H. T. T. (2015). The effect of capital structure on corporate performance: Evidence in Vietnam. International Journal of Business and Administrative Studies, 1(2), 68-77. doi:https://doi.org/10.20469/ijbas.10004-2

Hassan, A. E. (2009). Predicting faults using the complexity of code changes. In Proceedings of the 31st International Conference on Software Engineering, Tokyo, Japan.

Islami, X., Mulolli, E., \& Mustafa, N. (2018). Using management by objectives as a performance appraisal tool for employee satisfaction. Future Business Journal, 4(1), 94-108. doi:https://doi.org/10.1016/j.fbj.2018.01.001

Katzenbach, J., \& Smith, D. (2005). The discipline of teams. Harvard Business Review, 4(7), 45-60. 
Kurniawati, E. P., \& MeilianaIntani, A. (2016). Effect analysis of the use of accounting information, managerial performance and employee performance towards SMEs. Journal of Administrative and Business Studies, 2(3), 130-142. doi:https:// doi.org/10.20474/jabs-2.3.4

Mahdieh, O. (2015). Interaction between communication and organizational conflict and its relationship with performance. International Journal of Business and Administrative Studies, 1(2), 54-60. doi:https://doi.org/10.20469/ijbas.10002-2

Meyer, M. W., \& Gupta, V. (1994). The performance paradox. Research in Organizational Behaviour, 16, $309-369$.

Muenthaisong, K., \& Leemanonwarachai, T. (2016). An investigation of china's import demand for Technically Specified Natural Rubber (TSR) from Thailand. International Journal of Business and Economic Affairs, 1(1), 21-28. doi:https:// doi.org/10.24088/ijbea-2016-11004

Noe, R. A., Hollenbeck, J. R., Gerhart, B., \& Wright, P. M. (2006). Human resource management: Gaining a competitive advantage. New York, NY: McGraw-Hill/Irwin.

Northrop, L., Feiler, P., Gabriel, R. P., Goodenough, J., Linger, R., Longstaff, T., ... others (2006). Ultra-large-scale systems: The software challenge of the future (Tech. Rep.). Software Engineering Institute, Carnegie Mellon University, Pittsburgh, PA.

Porter, M. E., \& Heppelmann, J. E. (2014). How smart, connected products are transforming competition. Harvard Business Review, 92(11), 64-88.

Rahman, M. A., \& Qi, X. (2016). Core Banking Software (CBS) implementation challenges of e-banking: An exploratory study on Bangladeshi banks. Journal of Administrative and Business Studies, 2(4), 208-215.

Ramasubbu, N., \& Balan, R. K. (2007). Globally distributed software development project performance: an empirical analysis. In Proceedings of the the 6th Joint Meeting of the European Software Engineering Conference and the ACM SIGSOFT Symposium on The Foundations of Software Engineering, New York, NY.

Sawyer, S., \& Guinan, P. J. (1998). Software development: Processes and performance. IBM Systems Journal, 37 (4), $552-569$. doi:https://doi.org/10.1147/sj.374.0552

Sharkie, R. (2009). Trust in leadership is vital for employee performance. Management Research News, 32(5), 491-498. doi:https://doi.org/10.1108/01409170910952985

Sirota, D., \& Klein, D. (2013). The enthusiastic employee: How companies profit by giving workers what they want. Upper Saddle River, NJ: FT Press.

Sobhani, A., Wahab, M. I. M., \& Neumann, W. P. (2017). Incorporating human factors-related performance variation in optimizing a serial system. European Journal of Operational Research, 257(1), 69-83. doi:https://doi.org/10.1016/ j.ejor.2016.06.057

The Himalayan. (2018). Espouse e-economy. Retrieved from https://bit.1y/2DV9VC9 (accessed on 2 October, 2018)

Tsai, M. S., \& C, T. M. (2017). The influence of loyalty, participation and obedience on organizational citizenship behavior. International Journal of Business and Economic Affairs, 2(1), 67-76. doi:https://doi.org/10.24088/ijbea-2017-21009

Vosloban, R. I. (2012). The influence of the employee's performance on the company's growth - a managerial perspective. Procedia Economics and Finance, 3(5), 660-665. doi:https://doi.org/10.1016/S2212-5671(12)00211-0

Waggoner, D. B., Neely, A. D., \& Kennerley, M. P. (1999). The forces that shape organisational performance measurement systems: An interdisciplinary review. International Journal of Production Economics, 60(5), 53-60. doi:https://doi .org/10.1016/s0925-5273(98)00201-1

Wrzesniewski, A., \& Dutton, J. E. (2001). Crafting a job: Revisioning employees as active crafters of their work. Academy of Management Review, 26(2), 179-201. doi:https://doi.org/10.5465/amr.2001.4378011

Xtend, D. (2017). Top eight software development companies in nepal. Retrieved from https://bit.1y/2HTeoJu (accessed on September 29, 2018)

Zahra, S. A., \& Bogner, W. C. (2000). Technology strategy and software new ventures' performance: Exploring the moderating effect of the competitive environment. Journal of Business Venturing, 15(2), 135-173. doi:https://doi.org/10.1016/ s0883-9026(98)00009-3 